\title{
PROGRAMAS DE MATERIAIS DIDÁTICOS PARA A EJA NO BRASIL (1996- 2014): TRAJETÓRIA E CONTRADIÇÕES
}

\section{PROGRAM TEACHING MATERIALS FOR ADULT EDUCATION IN BRAZIL (1996- 2014): HISTORY AND CONTRADICTIONS}

\author{
MELLO, Paulo E. D. \\ paulodemello04@gmail.com \\ UEPG - Universidade Estadual de Ponta Grossa
}

\begin{abstract}
RESUMO A Educação de Jovens e Adultos (EJA), no Brasil, tornou-se modalidade específica da Educação Básica com a Lei de Diretrizes e Bases da Educação Nacional, em 1996, reafirmando o direito público subjetivo dos jovens e adultos à educação. Desde então, várias lutas têm sido travadas para efetivar este direito por meio dos instrumentos da política educacional destinados à manutenção e funcionamento da EJA nos sistemas públicos de ensino. Dentre eles, destacam-se os programas de assistência ao estudante que visam a prover condições de acesso e permanência na escola, tais como os programas de transporte escolar, alimentação e materiais didáticos. Neste artigo, são apresentadas e analisadas a trajetória e contradições da constituição dos programas de materiais didáticos destinados à EJA, desenvolvidos no âmbito da União desde 1996 até 2014. Constata-se, ao longo destes anos, distintas formas de condução das políticas para EJA e que, apesar dos avanços obtidos em termos de recursos financeiros e suporte pedagógico, observados especialmente nos últimos anos, ainda persistem contradições que contribuem para uma descaracterização da EJA como espaço de propostas plurais de oferta e organização de cursos atentos à diversidade característica de seu público.
\end{abstract}

PALAVRAS-CHAVE: Educação de Jovens e Adultos. Livro Didático. PNLD-EJA. Programas de Materiais Didáticos.

ABSTRACT The Education for Youth and Adults in Brazil became specific modality of Basic Education with the Law of Guidelines and Bases of National Education in 1996, reaffirming the subjective public right of young people and adults to education. Since then several fights have been waged to enforce this right through the instrument of education policy for the maintenance and operation of adult education in public school systems. Among them stand out assistance programs aimed at providing the student admission and stay in school, such as school programs, transportation, food and materials. This paper presents and analyzes the history and contradictions of the constitution of instructional materials programs for Youth and Adult Education developed within of the Union from 1996 to 2014. Is observed over the years different forms of implementing policies to EJA, and that despite the progress achieved in terms of financial resources and educational support, observed especially in recent years, contradictions that contribute to a distortion of space like EJA persist plural proposed offering and organization attentive to the characteristic diversity of its public courses.

KEYWORDS: PNLD-EJA. Programs Instructional Materials. Textbook. Youth and Adult Education. 


\section{INTRODUÇÃO}

No Brasil, as lutas pela ampliação das oportunidades de escolarização para jovens e adultos que não concluíram a Educação Básica representam as tentativas de resgate de uma dívida social histórica. Segundo dados estatísticos atuais, cerca de 65 milhões de brasileiros possuem menos de oito anos de estudos e, aproximadamente, 12 milhões são analfabetos ${ }^{1}$. Na Lei de Diretrizes e Bases da Educação Nacional (LDBEN), de 1996, a Educação de Jovens e Adultos (EJA), passou a ser uma modalidade específica da Educação Básica com o objetivo de assegurar uma oferta educacional qualificada para essa ampla parcela da população. Um dos elementos que visam a prover condições de permanência e sucesso nos estudos são os materiais didáticos (em especial dos livros didáticos) oferecidos aos alunos, que necessitam ser adequados ao perfil e às necessidades dos estudantes da EJA.

O fomento ou produção, pelo Estado Brasileiro, de materiais didáticos destinados a professores e alunos da EJA tem sido uma característica das políticas de implementação e desenvolvimento dessa modalidade de ensino no Brasil que remonta aos momentos fundantes da EJA como preocupação de política educacional pública no país. Segundo Beisiegel (2004), já na primeira Campanha de Educação de Adultos (CEA) lançada no país, em 1947, a atuação do poder público na produção ou no fomento à produção de materiais didáticos para o desenvolvimento da leitura, escrita, operações básicas de matemática, noções de cidadania, higiene e saúde, geografia e história, dentre outros, foi significativa. No período da realização da CEA, que se estende até meados dos anos 1950, a União realizou a articulação com os governos estaduais e municipais, e mobilizou o apoio da sociedade civil organizada, envolvendo diferentes sujeitos na produção de recursos didáticos ${ }^{2}$.

\footnotetext{
${ }^{1}$ Instituto Brasileiro de Geografia e Estatística - IBGE - Pesquisa Nacional por Amostra de Domicílios - PNAD - 2011. Disponível em

<http://www.ibge.gov.br/home/presidencia/noticias/imprensa/ppts/00000010135709212012572220530 659.pdf $\geq$ Acesso em: 02 nov. de 2013

${ }^{2}$ Nas pesquisas sobre EJA o tema dos materiais didáticos tem como referência os trabalhos de Fávero $(1984,2006,2007$, s/d), Beisiegel $(1984 ; 2004)$ e Paiva (1984), que abordam os materiais didáticos produzidos no âmbito dos programas e ações desenvolvidos no país desde a década de 1940.
} 
O tema dos materiais didáticos, seu lugar nas políticas da União ${ }^{3}$ e suas relações com as propostas e os métodos de educação de jovens e adultos no Brasil tornou-se tema fundamental nas discussões no início dos anos 1960, momento de eclosão de vários movimentos e engendramento de propostas de Educação Popular no país. Segundo Fávero (2007), pelo menos, desde então, a temática dos materiais didáticos passou a ocupar uma posição de destaque na pauta de debates sobre o tema, explicitando divergências entre as propostas educacionais, considerando o lugar atribuído aos materiais didáticos pré-elaborados, especialmente no processo de alfabetização. Mais recentemente, na década de 1990, vários documentos produzidos no país, pelos Fóruns de $\mathrm{EJA}^{4}$ e nos encontros nacionais de entidades ligadas à EJA, destacaram a produção de materiais didáticos como um elemento importante da viabilização das propostas e práticas educativas na EJA.

Neste trabalho, retomamos o período recente da história da educação brasileira, identificando quais foram as atuações da União na formulação e execução de políticas para EJA, com destaque à questão dos materiais didáticos. Exploramos, inicialmente, quais foram as linhas mestras dessas políticas implantadas durante os governos dos presidentes Fernando Henrique Cardoso (FHC) (1995 a 2002) e Luís Inácio Lula da Silva (2003 a 2010) e analisamos suas relações com a sociedade civil e o mercado editorial na produção de materiais didáticos para a EJA. Por fim, indicamos alguns dos impasses e desafios atuais que se impõem para a questão dos materiais didáticos para a EJA, após sua inserção no Programa Nacional do Livro Didático (PNLD).

\section{PRODUÇÃO DIDÁTICA PARA EJA NOS ANOS 1990: ENTRE CERTIFICAÇÃO E PRODUÇÕES COLETIVAS}

No campo da EJA, o período histórico que se estende entre os anos 1990 até 2002 (que antecede e se estende até o final do segundo mandato do presidente

\footnotetext{
${ }^{3}$ No Brasil a União representa o governo federal, cuja atribuição é desenvolver políticas públicas de âmbito nacional em regime de colaboração com Estados, Municípios e o Distrito Federal.

${ }^{4}$ O movimento dos Fóruns de Educação de Jovens e Adultos, surgiram no final da década de 1990, tendo como pauta atuar no processo de construção de políticas públicas de EJA, que assegurassem direitos na área da educação. $O$ movimento possui um Portal no seguinte endereço:<http://www.forumeja.org.br/>
} 
Fernando Henrique Cardoso - FHC) foi tensionado pelos embates travados em torno dos marcos legais da EJA e das lutas pela implantação de políticas concretas que assegurassem as conquistas obtidas. Na expressão de Haddad (2007), a década foi marcada pelos embates entre as conquistas formais de direitos e a negação real pelas políticas. Assim, por um lado, desenvolveram-se os enfrentamentos promovidos por segmentos que buscavam assegurar avanços no arcabouço legal que se formulava no país, a partir da Constituição de 1988, no Plano Decenal de Educação para Todos de 1993, na Lei de Diretrizes e Bases da Educação Nacional de 1996, na Lei no 9.424/96 que cria o Fundo de Manutenção do Ensino Fundamental e Valorização do Magistério (FUNDEF), nas discussões sobre Diretrizes Curriculares Nacionais e no Plano Nacional de Educação de 2001. Por outro lado, desenvolveram-se as lutas pela efetiva implantação das normas legais pelos agentes públicos por meio de políticas que garantissem os avanços obtidos.

Entre 1997 e 2002, durante o governo FHC, o Fundo Nacional de Desenvolvimento da Educação (FNDE), uma autarquia federal ligada ao Ministério da Educação, passou a responder pelo apoio financeiro da União aos Estados e Municípios para programas de ensino fundamental de jovens e adultos. As iniciativas de alfabetização e capacitação profissional de jovens e adultos da União passaram a ser coordenadas por setores não educacionais do governo federal, caracterizandose por intervenções focalizadas ou de caráter compensatório, destinadas a atender prioritariamente as regiões mais pobres do país, destacando-se o Conselho da Comunidade Solidária, no caso do Programa Alfabetização Solidária (PAS); o Ministério do Trabalho e Emprego, no caso do Plano Nacional de Qualificação Profissional (PLANFOR); e o Ministério do Desenvolvimento Agrário, no caso do Programa Nacional de Educação na Reforma Agrária (PRONERA). (DI PIERRO; GRACIANO, 2003)

Nesse contexto, a Coordenação de Educação de Jovens e Adultos - COEJA, no Ministério da Educação, desenvolveu uma série de iniciativas voltadas à reformulação de referenciais curriculares, disseminação de materiais didáticos e implantação de um programa de formação de educadores das redes de escolas estaduais e municipais. Assim, após a elaboração e aprovação das novas Diretrizes Curriculares Nacionais (DCN), em 2000, foram formulados novos Parâmetros 
Curriculares Nacionais para a EJA (PCN/EJA) e um novo modelo de certificação de estudos: o Exame Nacional de Certificação de Competências de Jovens e Adultos (ENCCEJA).

Estes instrumentos normativos articulados demonstravam a intenção da União de fornecer elementos para a reorganização do quadro da EJA no país, subsidiando e reorientando as políticas dos demais agentes públicos ou privados que atuavam no setor, tais como as secretarias estaduais e municipais de educação, os sindicatos, os movimentos sociais, as organizações não governamentais, dentre outros agentes sociais. Este processo envolveu uma série de situações contraditórias e resultou em diferentes embates envolvendo os agentes sociais ligados à EJA, que se articulavam especialmente em torno dos Fóruns do setor.

De fato, é no movimento das reformas educativas do governo $\mathrm{FHC}$ que as articulações entre currículo, produção didática e, posteriormente, os exames passam a ter destaque como instrumentos combinados de uma política educacional destinada a conformar uma proposta para a EJA. Na realidade, esse processo iniciase em meados dos anos 1990, com a elaboração da proposta curricular para o primeiro segmento da EJA e a produção de uma coleção didática a ela vinculada, denominada "Viver é Aprender". A iniciativa da elaboração curricular coube à Ação Educativa, organização não governamental que atua na área de educação e juventude. Em 1996, o MEC coeditou e distribuiu essa proposta curricular após manifestar sua intenção à Comissão Nacional de Educação de Jovens e Adultos (CNAEJA). Alguns anos depois, em 2000, deu continuidade a essa iniciativa e organizou a Proposta Curricular para o Segundo Segmento do Ensino Fundamental da Educação de Jovens e Adultos - EJA (correspondente à etapa de $5^{\mathrm{a}}$ a $8^{\mathrm{a}}$ séries do Ensino Fundamental), mas dela não decorreu nenhuma proposta oficial para produção de material didático. A elaboração de material didático ocorreria apenas em 2002, mas já como parte do processo de formulação do exame nacional de certificação de competências da EJA, o ENCCEJA. Dessa forma, ao longo do governo FHC, a questão do material didático para EJA passou de uma conformação orientada pelo currículo prescrito para uma nova forma de configuração definida pelo currículo avaliado, ou seja, os exames de certificação. 
Ao mesmo tempo em que desenvolvia esta política centralizada de currículo e avaliação no ano de 2001, mas com tempo previsto de execução até 2003, foi lançado o Programa de Apoio a Estados e Municípios para a Educação Fundamental de Jovens e Adultos, denominado Programa Recomeço - Supletivo de Qualidade, integrado ao Projeto Alvorada. O governo preconizava articular as ações da EJA a um conjunto de programas sociais, de infraestrutura e desenvolvimento que, em tese, estariam voltados para a redução das desigualdades regionais e melhoria das condições de vida nas localidades mais carentes do Brasil. O objetivo do Programa Recomeço era apoiar, com recursos financeiros, estados das regiões Norte e Nordeste e municípios de microrregiões com baixo Índice de Desenvolvimento Humano (IDH); e prover ensino fundamental de jovens e adultos, assegurando a continuidade de estudos aos egressos do Programa Alfabetização Solidária - PAS. Dentre suas ações, o PAS previa a aquisição de livro didático ou módulo e/ou impressão de material didático adequado à Educação de Jovens e Adultos do Ensino Fundamental, $1^{\circ}$ e $2^{\circ}$ segmentos; bem como a aquisição e reprodução de materiais didáticos e pedagógicos.

Portanto, as atuações da União, no período do governo FHC, no âmbito do $\mathrm{MEC}$, relacionadas à produção didática para a EJA, foram marcadas pelo Programa Recomeço, criado para complementar os recursos destinados à EJA, e que financiou a produção de materiais didáticos pelas secretarias municipais e estaduais; e pelo PAS, que adotou a coleção "Viver é Aprender!" e desenvolveu, junto de seus parceiros, materiais para a campanha de alfabetização. A produção didática passa a ser ferramenta de controle da oferta da EJA, vinculando-se à questão do currículo e articulando-se aos exames de certificação por meio do ENCCEJA. A política do governo FHC oscila entre a descentralização de recursos para a produção didática localizada e a definição de instrumentos normativos - currículos e exames - que definem formas e conteúdos para essa produção. Não há, no contexto dos governos FHC, qualquer movimento visando a criar mecanismos de avaliação dos materiais produzidos ou vincular a produção a um programa de aquisição em larga escala como o Programa Nacional do Livro Didático, o PNLD.

Por outro lado, além dos materiais didáticos que resultam das ações da União, vários outros surgem como resultado de iniciativas de governos municipais 
ligados à gestão de partidos considerados progressistas, como o Partido dos Trabalhadores - PT, cuja experiência na prefeitura de São Paulo, com a presença de Paulo Freire à frente da Secretaria da Educação, em 1990, foi fonte de inspiração para o resgate de experiências anteriores à Ditadura Militar, nas quais a participação da sociedade civil era fundamental para promover a inclusão educacional das parcelas pobres da população.

Foi nesse contexto, por exemplo, que surgiu o Movimento de Alfabetização Mova. O Mova espalhou-se por todo o país, em governos municipais e estaduais de diversos partidos, mas principalmente nas gestões do Partido dos Trabalhadores PT. De acordo com Haddad (2007), o modelo implementado, ao envolver entidades e movimentos sociais, acabou por fortalecer, no âmbito da sociedade civil, a demanda por EJA e por experiências educacionais, as quais estimulavam a produção de materiais didáticos, coletivamente, por professores e estudantes.

Algumas prefeituras municipais também protagonizaram, por meio de suas equipes pedagógicas, a produção de materiais didáticos significativos. Em Porto Alegre, foram editados, pelo Sistema de Educação de Jovens e Adultos (SEJA), os livros "Palavras de trabalhador", produtos da experiência educativa realizada com jovens e adultos trabalhadores. Em Goiás, como resultado de uma parceria entre o MEB, a secretaria municipal de Goiânia e o Instituto Brasil Central da Diocese de Goiânia, foram elaborados alguns materiais didáticos. Assim, durante a década de 1990, vários materiais foram produzidos no âmbito das experiências educativas, patrocinadas por prefeituras progressistas ou desenvolvidas por ONGs, ligadas aos princípios dos movimentos de educação e cultura popular.

Além dessas produções, instituições ligadas ao movimento dos trabalhadores, como a Central Única dos Trabalhadores (CUT), em parceria inicial com a PUC/SP e, depois, com a Universidade Federal do Rio de Janeiro - UFRJ, a Unitrabalho e o DIEESE, produziram materiais didáticos significativos no interior dos programas Integrar e Integração. Também o Movimento dos Trabalhadores Sem-Terra - MST desenvolveu materiais didáticos para serem utilizados nos seus acampamentos e assentamentos $^{5}$.

\footnotetext{
${ }^{5}$ Os materiais didáticos da CUT, do SEJA de Porto Alegre e do MST, foram analisados por Fávero (2007).
} 
O segmento das editoras comerciais, a partir de finais dos anos 1990, também viveu um cenário de expansão propiciado pelo processo de consolidação dos cursos de EJA, especialmente quando, em 1998, o Fundo Nacional de Desenvolvimento da Educação (FNDE) passou a apoiar estados e municípios na produção e aquisição de materiais por meio do Programa Recomeço. A facilidade de uso dos recursos promoveu a presença de editoras com produção didática destinada à EJA em praticamente todas as regiões do país, com exceção do Centro-Oeste. Mesmo assim, verificou-se uma concentração do mercado, com $36 \%$ das editoras sediadas em São Paulo, 21\% em Curitiba e 15\% em Fortaleza. Além disso, a produção destinada à EJA revelou estratégias comerciais e dispositivos editoriais que apontaram uma produção de baixa qualidade editorial, seja do ponto de vista da materialidade ou do conteúdo escolar ${ }^{6}$.

\section{PRODUÇÃO DIDÁTICA PARA EJA NO GOVERNO LULA: AVANÇOS E CONTRADIÇÕES}

A partir de 2003, no governo de Luís Inácio Lula de Silva, as reformas educativas efetuadas na gestão anterior passaram a ser objeto de reconsiderações e revisões. O próprio MEC sofreu várias reformulações com a reorganização de sua estrutura. Programas, projetos e ações do Ministério foram, aos poucos, reorientados. Para enfrentar a questão do analfabetismo, por exemplo, foi criado o Programa Brasil Alfabetizado, o PBA, em 2003. A EJA, nesse processo de reformulação da política educacional, passou a ser responsabilidade da Secretaria de Educação Continuada e Diversidade, a SECAD, criada em 2004. O Programa Recomeço foi rebatizado de Fazendo Escola, sofreu algumas alterações, e foi progressivamente estendido a todas as regiões do país, com valores per capita diferenciados em uma escala proporcional ao déficit educativo das localidades.

No novo contexto dado pela criação da SECAD, a atuação da União em relação à produção didática voltada à EJA dividiu-se entre a elaboração, pelo MEC,

\footnotetext{
${ }^{6}$ Veja-se a respeito Mello (2010), onde analiso detalhadamente a produção didática de EJA das editoras comerciais indicando as estratégias editoriais que comprometem a qualidade da produção. Disponível em: <http://www.teses.usp.br/teses/disponiveis/48/48134/tde-26012011-142038/pt-br.php> Acesso em: 30 jun. de 2012.
} 
de uma proposta de material didático de caráter interdisciplinar e flexível, como a coleção Cadernos de EJA (2007) que foi articulada à formação do professor por meio da coleção Trabalhando com EJA (2006a) e a produção de novos materiais didáticos voltados à promoção da leitura dos jovens e adultos recém alfabetizados, como a coleção Literatura para Todos (2006b), assim como a manutenção da política de transferência de recursos financeiros aos entes federados por meio de programas como o Fazendo Escola e o PBA e de materiais vinculados aos exames de certificação, o ENCCEJA.

A criação do Programa Nacional do Livro Didático para a Alfabetização de Jovens e Adultos - PNLA, em 2007 (Resolução n 18, de 24 de abril de 2007), no âmbito do PBA, representa um momento de inflexão da política de materiais didáticos até então implementada, ao incluir a EJA no Programa Nacional do Livro Didático - PNLD, ainda que, naquele momento, atendendo apenas ao segmento de alfabetização. Com o fim do Programa Fazendo Escola e a inclusão da EJA no FUNDEB, a política da SECAD desloca-se da transferência de recursos para entidades que promovem a EJA, para o investimento financeiro em programas que estimulam a produção centralizada de materiais didáticos. $O$ foco da política de materiais didáticos para a EJA passa a ser a aquisição e distribuição do livro didático, strictu sensu, beneficiando as grandes editoras do mercado.

Mantendo essa tendência, as edições do PNLA de 2009 e 2010 ampliaram o universo de alunos atendidos, passando a incorporar, além dos alfabetizandos inscritos no PBA, as turmas regulares de alfabetização existentes nas redes públicas de ensino e matriculadas na Educação de Jovens e Adultos. Por fim, ainda em 2009, o PNLA foi extinto e incorporado a um novo programa, mais amplo: o Programa Nacional do Livro Didático para a Educação de Jovens e Adultos (PNLD-EJA/2011).

O PNLD-EJA pode ser considerado uma importante conquista para a EJA no Brasil. Criado pela Resolução $n^{\circ} 51$, de 16 de setembro de 2009, ele ampliou o PNLA, passando a distribuir obras didáticas para além das entidades parceiras do Programa Brasil Alfabetizado, atingindo todas as escolas públicas com turmas do $1^{\circ}$ ao $9^{\circ}$ ano do Ensino Fundamental da EJA. Na edição de 2014, o PNLD-EJA avançou ainda mais ao incorporar todas as etapas da Educação Básica, desde a alfabetização, passando pelos anos iniciais e finais do Ensino Fundamental, até 
chegar ao Ensino Médio. Esta iniciativa representou um importante momento de consolidação de uma política que buscava definir novos padrões de qualidade para a produção de obras didáticas para a EJA, afirmando-se como um amplo programa de aquisição e distribuição de obras didáticas destinadas especificamente às aprendizagens e educação do público jovem e adulto. Todavia, o modelo adotado para o funcionamento do programa acabou por acelerar contradições que, a nosso entender, comprometem características da produção didática destinada à EJA, e que precisariam ser preservadas, como a diversidade dos produtores e a flexibilidade e variedade dos materiais.

Em sua primeira edição, no ano de 2011, o programa atendeu cerca de quatro milhões de estudantes e professores, tendo distribuído aproximadamente 17 milhões de livros.

Quadro 1: Resultado do processo de avaliação do PNLD-EJA 2011 (n de obras)

\begin{tabular}{|l|c|c|c|}
\hline Etapa da EJA & Avaliadas & Aprovadas & Reprovadas \\
\hline Alfabetização & 27 & 14 & 13 \\
\hline $1^{\circ}$ segmento & 14 & 03 & 11 \\
\hline $2^{\circ}$ segmento & 10 & 02 & 08 \\
\hline $\begin{array}{l}\text { Regionais de História } \\
\text { e Geografia }\end{array}$ & 14 & 02 & 12 \\
\hline Total & 65 & 21 & 44 \\
\hline
\end{tabular}

Fonte: FNDE/ Relatório PNLD-EJA, 2011. Elaboração do autor

Os resultados do processo de avaliação do PNLD-EJA 2011, por exemplo, indicaram que apenas $32 \%$ das obras avaliadas foram aprovadas, revelando uma forte defasagem do material didático em relação às necessidades dos estudantes da EJA. Mas o fato de já ter havido um processo de avaliação, por conta do PNLA, mascara o resultado. Muitas obras aprovadas no PNLD-EJA já haviam sido aprovadas no PNLA. Assim, se considerarmos a avaliação dos livros do $1^{\circ}, 2^{\circ}$ segmentos e regionais que nunca haviam sido submetidos à avaliação, verificamos que o índice de aprovação foi de apenas $21 \%$ das obras. O elevado índice de reprovação revela, portanto, a baixa qualidade pedagógica do material destinado à EJA produzido no país pelo mercado editorial, mesmo tendo sido elaborado um edital que especificava as características consideradas desejáveis nas obras. Ao 
que parece, as editoras lançaram-se ao processo de avaliação sem terem investido na produção cuidadosa das obras segundo os critérios pedagógicos pelos quais elas seriam avaliadas.

Assim, um aspecto que tem sido revelado por alguns estudos ${ }^{7}$ é que o processo de avaliação do PNLD-EJA está depurando a qualidade da produção didática destinada à EJA. Na edição do PNLD-EJA de 2014, o índice de aprovação foi de $46 \%$ das obras inscritas. Apesar dos avanços, o elevado índice de reprovação ( $54 \%$ das obras) revela que ainda persiste uma baixa qualidade pedagógica do material destinado à EJA produzido no país pelo mercado editorial.

Os resultados também revelam um processo de concentração da produção didática que beneficia as editoras mais aparelhadas e competitivas do mercado editorial. Essa dinâmica de concentração do mercado editorial já podia ser observada na edição de 2011. Naquela edição, das 11 editoras que tiveram coleções aprovadas, apenas três, todas situadas no estado de São Paulo, a Ática (quatro coleções), FTD (cinco coleções) e Global (três coleções) concentraram 57\% das obras aprovadas. Outro aspecto é que duas das três coleções aprovadas no PNLD-EJA pela editora Global já haviam sido produzidas e distribuídas pelo próprio MEC no governo FHC. Com o fim do governo FHC, a Ação Educativa que detinha os direitos autorais da coleção passou a publicá-la pela editora Global. Com isso, o número de obras que podemos considerar inéditas e que foram aprovadas reduz-se a escassos $10 \%$ das coleções avaliadas.

$\mathrm{Na}$ edição de 2014 , esse processo se acentuou, pois $78 \%$ dos títulos aprovados são de editoras com sede em São Paulo e $22 \%$ são do Paraná, sendo que apenas quatro editoras concentraram $78 \%$ das obras aprovadas. No Ensino Médio, a situação ficou ainda mais grave, pois, na avaliação de 2014, apenas uma única obra foi aprovada, criando virtualmente uma situação de monopólio da produção didática para a EJA destinada ao Ensino Médio; além de criar uma situação de falsa liberdade de escolha para as redes de ensino, uma vez que a opção seria entre ter nenhuma obra ou escolher a aprovada. É preciso garantir

\footnotetext{
${ }^{7}$ Veja-se por exemplo: MELLO, Paulo Eduardo Dias de. Public policies for the production of textbooks for youth and adults in Brazil books: some reflections on recent historical trajectory. In: Macerata: EUM-Edizioni Università di Macerata, 2014. CASSIANO, Célia Cristina de Figueiredo. O Mercado do Livro Didático no Brasil do Século XXI - A entrada do capital espanhol na educação nacional. São Paulo: Editora Unesp, 2013.
} 
mecanismos para que ao menos haja mais de uma opção para as escolas. Ainda que isso implique, por exemplo, em dar opção, para as escolas, de receberem recursos para impressão de materiais didáticos disponibilizados pelo próprio MEC, como o material didático do ENCCEJA e o Cadernos de EJA.

Por sua vez, o processo de escolha das obras e coleções didáticas, que se constitui uma das mais importantes etapas do PNLD-EJA, traz uma importante especificidade. Diferentemente do modo como ocorre no PNLD, onde as obras são escolhidas por escola, no PNLD-EJA esse processo deve ser organizado democraticamente em rede pelos sujeitos responsáveis pela adesão ao programa: 1- as Entidades do Programa Brasil Alfabetizado; 2- as Redes Públicas de Ensino (Municipais, Estaduais e do Distrito Federal); e 3- os Institutos Federais de Educação, Ciência e Tecnologia (IFET). São eles que devem mobilizar e assegurar condições de participação a todos os educadores envolvidos com a EJA em suas respectivas entidades. Ao final do processo, cabe a um único responsável, designado pela entidade (redes municipais, estaduais, e IFETs), o registro das obras e/ou coleções escolhidas que representem a decisão da maioria dos educadores, obtida por meio da mobilização e do debate democrático em torno da proposta de EJA assumida pela entidade e que será destinada a todas as escolas da rede de ensino.

É exatamente sobre este ponto que reside, atualmente, uma das maiores contradições do PNLD-EJA. Entendemos que, se há um acerto fundamental do programa ao defender o princípio da EJA como uma modalidade de ensino muito complexa, há também um grande equívoco ao definir o processo de escolha das obras e coleções que, mesmo participativa, faz prevalecer uma forma centralizada de decisão que desconsidera a diversidade de modos de organização que caracterizam a EJA, principalmente nos estados e municípios.

De modo geral, sabemos que as redes municipais de ensino devem ser responsáveis prioritariamente pela oferta da EJA em programas de alfabetização como o PBA - e nos Anos Iniciais e Finais do Ensino Fundamental; enquanto as redes estaduais devem, destacadamente, responsabilizar-se pela oferta da EJA no Ensino Médio, integrada ou não à profissionalização. Mas a realidade da oferta de EJA no país é bastante diversa e complexa, existindo muitos casos em que essa 
oferta pode seguir padrões distintos em cada unidade da federação. Assim, por exemplo, a matrícula da EJA nos anos iniciais e finais do Ensino Fundamental nas redes estaduais pode até superar as matrículas da rede municipal, fazendo com que o estado também tenha fortes responsabilidades para com o Ensino Fundamental da EJA. Isso significa dizer que algumas redes estaduais possuem escolas de EJA em uma grande quantidade de municípios que se espalham pelas diferentes realidades territoriais locais.

Dessa forma, ainda que o processo de escolha das obras possa ser efetivamente participativo e democrático, ele é incapaz de atender às diversas realidades locais que caracterizam as redes estaduais de ensino, ou mesmo as realidades diversas e singulares que caracterizam os bairros de um mesmo município. Afinal, como atender às especificidades de todas as escolas senão atendendo ao que está sendo proposto em seu projeto político pedagógico? Se a identidade da EJA é a diversidade, o processo de escolha deve fortalecer esta característica e não confrontá-la pela escolha de uma única obra ou coleção didática que passa a atender a toda uma rede de ensino.

$\mathrm{Na}$ prática, esse processo centralizado de escolha atropela as características que mais deveriam ser objeto de respeito e consideração do Programa, e que estão asseguradas na Lei n 9.394/96 - Lei de Diretrizes e Bases da Educação Nacional (LDBEN/96) que define, em seu artigo $4^{\circ}$ - inciso VII, que é

dever do Estado ofertar educação escolar regular para jovens e adultos, com características de modalidade, garantido àqueles que forem trabalhadores as condições de acesso e permanência na escola e respeitando as características adequadas às necessidades e disponibilidade desse público. [...]

Lembramos ainda que o perfil do aluno da EJA e suas situações reais devem se constituir em princípio da organização do projeto pedagógico dos estabelecimentos, de acordo com o art. 25 da LDBEN. Aliás, este tem sido um dos objetivos das redes de ensino ao buscar formas de ampliar a autonomia didática e pedagógica das escolas, assegurando-as formas de organizar a oferta e o currículo da EJA, respeitando a legislação e as diretrizes vigentes, mas constituindo espaços de identidade político-pedagógica aos seus projetos. 
Por isso, entendemos que há uma necessidade urgente de reformulação do processo de escolha das obras pelas redes de ensino e entidades do PBA. É preciso empoderar as entidades do PBA e especialmente as escolas das redes de ensino, para que possam definir, de acordo com seu Projeto Pedagógico, as obras didáticas que são mais adequadas aos jovens e adultos estudantes da EJA. Não é concebível que redes marcadas pela diversidade tenham que centralizar as escolhas, desfigurando o trabalho pela autonomia pedagógica das escolas e seus coletivos.

Depreende-se, do que vimos afirmando até aqui, que as características do PNLD-EJA têm afetado o campo de produção didática da EJA, fortalecendo as grandes editoras capazes de produzir materiais didáticos, concentrando essa produção e podendo criar um efeito de homogeneização das propostas curriculares, induzido pelo processo de escolha centralizado que define a escolha de uma única obra para toda uma rede de ensino, sem respeitar as singularidades de cada unidade escolar.

Outro elemento central da política de materiais didáticos, no governo Lula, foi a produção de material literário destinado ao público da EJA. Para tanto, foi criado, em 2005, o Concurso Literatura para Todos, com o objetivo de estimular a produção literária destinada a jovens, adultos e idosos em processo de alfabetização. Segundo Maciel (2007), a produção do material literário da coleção procurou atender às especificidades da EJA, o chamado "neoleitor", desde seu projeto editorial:

A coleção destaca-se por seu projeto gráfico. Foi avaliado que o tamanho dos textos literários em circulação, a complexidade da forma, a falta de intimidade com autores e obras deixam à margem excelentes oportunidades de aproximar os neoleitores dos textos literários. [...] No projeto gráfico considerou-se também que os livros precisariam ser ao mesmo tempo atraentes e práticos e para isso foram selecionados diversos estilos de ilustrações que dialogam com o texto e o universo do neoleitor. A coleção tem um formato e uma mancha gráfica que pretende favorecer a aproximação do neoleitor com o texto e tornar os livros simples e bonitos (MACIEL, 2007, p.3).

Mas, a partir de 2009, seguindo uma nova diretriz da política de materiais didáticos, pautada pela inclusão da EJA em editais gerais destinados à educação básica, a SECAD promoveu a chamada de obras literárias destinadas a todos os segmentos da EJA no edital do Programa Nacional Biblioteca da Escola - PNBE. O desafio que o PNBE trouxe foi como identificar obras literárias que atendessem ao 
público da EJA. Isso rompia com lógica do Concurso Literatura para Todos que previa a elaboração de textos exclusivamente pensados para o público da EJA. De certo modo, a inserção da EJA no PNBE questionou a necessidade de produção ou mesmo a existência de materiais literários em formatos específicos para o público da EJA, indicando disjunções entre iniciativas do próprio MEC.

Para equilibrar as estratégias de inserção da EJA nas ações da Educação Básica, a SECAD tomou algumas iniciativas de fomento à produção de materiais didáticos que não privilegiassem apenas grupos organizados de produtores ligados ao mercado editorial. Ainda no final do ano de 2008, foram lançadas duas resoluções voltadas à produção ou o fomento à produção de materiais didáticos diversos destinados à EJA. A Resolução $n^{\circ} 51$ visava ao fomento da produção de material pedagógico-formativo e de apoio didático de EJA, com ênfase na Economia Solidária. Por sua vez, a Resolução ${ }^{\circ} 44$ estimulava projetos da sociedade civil que deveriam contemplar a promoção de acesso à leitura e a formação de leitores e mediadores de leitura; a produção e distribuição de tecnologias educacionais de fomento à leitura e a pesquisa e avaliação sobre leitura.

Em suma, podemos dizer que a União, durante o governo Lula, por meio da SECAD, desenvolveu uma política de materiais didáticos para a EJA que oscilou entre o estímulo dirigido à produção de materiais didáticos diversos, mas com um perfil pedagógico e editorial definido, que deveriam favorecer os setores da sociedade civil; e as iniciativas de captação ou chamada pública de materiais didáticos por meio de editais conjuntos com a Secretaria de Educação Básica SEB, que, de certo modo, privilegiam segmentos organizados do mercado editorial com maior capacidade de atender aos rígidos critérios formais e técnicos de avaliação dos programas do livro, em especial o PNLD. Por outro lado, essas iniciativas de distribuição de materiais careceram de acompanhamento e avaliação sobre seus impactos nas práticas educativas da EJA e na produção didática para a modalidade, em particular do mercado de livros didáticos no Brasil, tendo gerado distorções que podem descaracterizar a EJA como espaço de propostas plurais.

Disto resulta, a nosso entender, a necessidade urgente de se repensar a dinâmica do PNLD-EJA, de modo a construir uma política mais ampla que possa atuar junto aos parceiros da EJA e ao mercado editorial, no sentido de provocar um 
movimento de qualificação do material existente e promover a elaboração de um número maior e diversificado da oferta de recursos pedagógicos para a EJA, evitando a concentração da produção e a opção exclusiva pelo livro didático e estimulando a produção dos materiais pelos próprios sujeitos. Por fim, se é necessário que uma política de materiais didáticos para EJA articule-se aos programas destinados a garantir a oferta de suportes educativos para a Educação Básica, é preciso pensar em mecanismos que protejam sua identidade políticopedagógica, sua tradição de protagonismo na produção didática e suas especificidades nos planos conceitual e metodológico.

\section{CONSIDERAÇÕES FINAIS}

Uma análise sobre as políticas públicas para produção didática destinada à EJA, nas últimas duas décadas, revela tensões, aproximações e contradições entre atuações do Estado, dos segmentos da sociedade civil e agentes do mercado provenientes da indústria cultural. Trata-se de uma trajetória marcada pela tensão entre continuidade e descontinuidade de programas educacionais e por disputas entre concepções distintas sobre que papel devem representar os materiais didáticos nos processos pedagógicos da EJA. Ela é, portanto, intrinsecamente vinculada às contradições do contexto histórico e aos embates em torno dos projetos sociais e propostas políticas educativas para a EJA. Destaca-se, por exemplo, o embate entre propostas que insistem na certificação de estudos ou na promoção de formas aceleradas e aligeiradas de formação para conclusão de estudos; e aquelas que projetam formas de educação continuada, numa perspectiva política de emancipação social, vinculadas às experiências de Educação Popular.

A tentativa de formulação de uma política específica para produção de materiais didáticos para a EJA foi aprofundada no governo Lula, não mais centrada apenas na articulação entre currículo prescrito, exames padronizados e materiais didáticos preparatórios como no governo de seu antecessor Fernando Henrique Cardoso. Este aprofundamento indicava uma pluralização de iniciativas, envolvendo uma diversidade de sujeitos produtores e o estímulo à produção de uma multiplicidade de materiais nos mais diferentes suportes, linguagens e conteúdo. 
Mas as contradições entre a inserção da EJA em um programa de aquisição e distribuição de livros em larga escala, vinculada ao mercado editorial e iniciativas de fomento à produção de propostas alternativas marcaram as gestões petistas.

As atuações recentes da União, sob os governos do PT, portanto, não asseguraram uma política articulada de fomento à produção e/ou aquisição de materiais didáticos para a EJA que contemplasse a diversidade das iniciativas dos sujeitos que atuam na EJA, e que se baseasse em critérios de avaliação comuns e específicos para os materiais produzidos, seja no âmbito dos programas oficiais ou das iniciativas apoiadas pelo Estado. Além disso, as próprias iniciativas oficiais se multiplicaram internamente na estrutura da União, e no âmbito de outras esferas, sobrepondo ações de secretarias e autarquias, algumas convergentes e outras que indicam divergências teóricas e práticas entre os projetos de EJA.

Há um consenso no campo educacional de que bons materiais didáticos são vetores da democratização do acesso à produção científica, didática e artísticocultural para o público da EJA. Mas, para que esses materiais possam cumprir uma função relevante na EJA, é preciso levar em consideração algumas dimensões importantes. A primeira é o contexto em que ocorre a aprendizagem: na EJA, a oferta de cursos possui grande flexibilidade de organização, de duração, de matriz curricular. Os cursos podem ser presenciais, semipresenciais, a distância; podem estar articulados à profissionalização ou não; podem ser ofertados em ambientes escolares, espaços educativos alternativos, etc. Outra dimensão é a diversidade do público, considerando a complexidade de sua formação e heterogeneidade social e cultural e as formas e ritmos diversos de aprendizagem. Nesse sentido, a forma como se organizam as propostas de aprendizagem, as atividades e interações sugeridas pelo material devem considerar como esse público aprende e as diferentes particularidades. Outro aspecto diz respeito às formas diferenciadas de seleção e organização dos conteúdos de aprendizagem que sejam significativos para a EJA, incluindo temas e abordagens que levem em consideração a rede de experiências e aprendizagens que jovens e adultos construíram em suas trajetórias de vida.

Assim, não basta ao Estado brasileiro, em especial à União, atuar como um mero distribuidor de materiais avaliados e adquiridos dos grandes produtores do 
mercado editorial. É preciso evitar o predomínio exclusivo do livro didático, como material didático, produzido em processos que conduzem a uma homogeneização curricular e levam à concentração dos recursos nas mãos das grandes editoras. Os materiais que envolvem novos suportes tecnológicos, que promovem inclusão digital, por exemplo, têm uma função relevante de proporcionar situações de aprendizagem de novos hábitos e de novas linguagens que invadem o cotidiano da vida contemporânea e que são ferramentas e elementos para novas aprendizagens.

Seria fundamental que a União assumisse o papel de articular suas ações nos marcos de uma política coerente, de forma a assegurar a pluralidade de sujeitos produtores, desde a sala de aula - com os professores atuando na produção de seus recursos didáticos - até os agentes da indústria cultural, garantindo padrões básicos de qualidade. Por isso, é preciso assegurar ações de fomento à produção de diferentes tipos de materiais, por distintos sujeitos, desde o chão das salas de EJA até as editorias das empresas educacionais, na diversidade de suportes, linguagens e tecnologias, incorporando múltiplas abordagens pedagógicas. Não podemos ignorar, na EJA, a forte tradição de processos de produção de materiais didáticos por docentes e alunos em processos e contextos formativos.

\section{PAULO EDUARDO DIAS DE MELLO}

Mestre e Doutor em Educação pela Universidade de São Paulo - USP. Professor adjunto do Curso de História da Universidade Estadual de Ponta Grossa/PR, docente do PPGH em História. Foi avaliador do PNLD da área de História e atuou na avaliação de livros didáticos, tecnologias educacionais e material didático para o MEC. Participou, como consultor, da concepção e coordenação do PNLD-EJA.

\section{REFERÊNCIAS}

BEISIEGEL, C. de R. Ensino Público e Educação Popular. In: PAIVA, V. (org.).

Perspectivas e Dilemas da Educação Popular. Rio de Janeiro: Edições Graal, 1984. p. 23-34.

BRASIL. CONGRESSO NACIONAL. Lei n 9.394, de 20 de dezembro de 1996. Estabelece as Diretrizes e Bases da Educação Nacional. Coletânea de leis da Casa Civil da Presidência da República: leis ordinárias. Brasília: Casa Civil, 1996. Disponível em: <http://www.planalto.gov.br/ccivil_03/Leis/L9394.htm.> Acesso em 15 jan. de 2015. 
. Estado e Educação Popular: um estudo sobre a educação de adultos. Brasília: Liber Livro Ed., 2004, 213p.

- Ministério da Educação/Secretaria de Educação Continuada, Alfabetização e Diversidade. Coleção Trabalhando com EJA. Brasília: MEC/SECAD, 2006a.

- Ministério da Educação/Secretaria de Educação Continuada, Alfabetização e Diversidade. Coleção Literatura para Todos. Brasília: MEC/SECAD, 2006b.

- Ministério da Educação/Secretaria de Educação Continuada, Alfabetização e Diversidade. Coleção Cadernos de EJA. Brasília, MEC/SECAD, 2007.

DI PIERRO, M. C; GRACIANO, M. Educação de Jovens e Adultos no Brasil: informe apresentado à Oficina Regional da UNESCO para América Latina e Caribe. Ação Educativa: São Paulo, 2003.

FÁVERO, O. Referências sobre materiais didáticos para a educação popular. In: PAIVA, V. (org.). Perspectivas e Dilemas da Educação Popular. Rio de Janeiro: Edições Graal, 1984, p. 48-56.

. Uma Pedagogia da Participação Popular: análise da prática educativa do MEB - Movimento de Educação de Base (1961/1966). Campinas, SP: Autores Associados, 2006, $306 \mathrm{p}$.

. Materiais Didáticos para a Educação de Jovens e Adultos. Cad. Cedes, Campinas, v. 27, n. 71, p. 39-62, jan./abr. 2007.

FÁVERO, O.; RIVERO, J. Educação de Jovens e adultos na América Latina: direito e desafio de todos. UNESCO, Fundação Santillana, sd. 96p.

FNDE. Relatório PNLD-EJA, 2011. Disponível em: <www.fnde.gov.br>. Acesso em: 05 dez. 2012.

HADDAD, Sérgio. Por uma nova cultura na educação de jovens e adultos, um balanço de experiências de poder local. In: Ação Educativa - Anais da $30^{\mathrm{a}}$. Reunião Anual da Anped: Caxambu, 2007, p. 34-45

MACIEL, I. M. Coleção Literatura Para Todos. MEC. 2006. Resenha publicada na Rev. Bras. Educ., v. 12, n. 36, p.3-9, Rio de Janeiro, set./dez. 2007

MELLO, P. E. D. Materiais Didáticos para a Educação de Jovens e Adultos: história, formas e conteúdos. 2010. 254p. Tese (doutorado). Faculdade de Educação. Universidade de São Paulo, São Paulo. 
Atos de Pesquisa em Educação - ISSN 1809-0354

Blumenau, v. 10, n.1, p.80-99, jan./abr. 2015

DOI: http://dx.doi.org/10.7867/1809-0354.2015v10n1p80-99

. Um novo olhar sobre a produção didática da EJA: as produções do meio escolar. Revista Brasileira de Educação de Jovens e Adultos, v. 1, n. 1, p. 101-118, 2013.

PAIVA, V. Educação Popular e Educação de Adultos. 2.ed. São Paulo: Edições Loyola, 1984, 368 p. 